\title{
多環芳香族炭化水素類の過冷却液体状態の蒸気圧 およびそ水らの粉じんへの吸着現象
}

\author{
（1984 年 1 月 5 日受理）
}

山崎裕 康*・桑田一弘・久下等生

\begin{abstract}
ガスクロマトグラフ法により，17種類の多環芳香族炭化水素 $(\mathrm{PAH})$ の $25^{\circ} \mathrm{C} に$ 打ける蒸気圧 $\left\{\left(\mathrm{P}_{1}\right)_{25}\right\}$

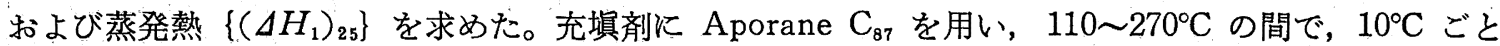
にノナデカン $\left(\mathrm{C}_{19}\right)$ の蒸気圧の対数に対して, $\mathrm{C}_{19}$ の保持時間に対する $\mathrm{PAH}$ の保持時間の比の対数 をプロットし，傾き $\left\{\left(1-\Delta H_{1} / \Delta H_{2}\right)\right\}$ 就よび切片（-C) を求めた。ついで, $\left(1-\Delta H_{1} / \Delta H_{2}\right),-C$ および $25^{\circ} \mathrm{C}$ に护ける $\mathrm{C}_{19}$ の蒸気圧, 蒸発熱 $\left(\Delta H_{2}\right)$ を用いて, 各 PAH の $\left(P_{1}\right)_{25}$ 㧊よび $\left(\Delta H_{1}\right)_{25}$ を求めた。 $\left(P_{1}\right)_{25}$ および $\left(\Delta H_{1}\right)_{25}$ は, $\mathrm{PAH}$ の固体の蒸気圧および蒸発熱から理論的に推定した $25^{\circ} \mathrm{C}$ に和ける過冷却状態の夜体の蒸気圧 $\left\{\left(P_{1 \mathrm{iq}}\right)_{25}\right\}$ 战よび蒸発熱 $\left(\Delta H_{1 \mathrm{iq}}\right)$ とよく一致した。大気中に和け る $\mathrm{PAH}$ 蒸気の粉じんへの吸着熱および気相中に存在する $\mathrm{PAH}$ と粉じん中に含まれている. PAH の 割合は， $\left(P_{1}\right)_{25}$ および $\left(\Delta H_{1}\right)_{25}$ を用いてうまく説明することができた。
\end{abstract}

\section{1 緒 言}

多環芳香族炭化水素（以下 $\mathrm{PAH}$ と略記する）は発がん性をも つ環境污染物質として古くから注目されておりり找り，環境中に抹 ける PAH の挙動を把握することは，環境科学に打いて重要な課 題である。通常, 環境大気中の $\mathrm{PAH}$ の挙動は種々の物性值を用 いて考察されている。たとえば, PAH の蒸気圧と蒸発熱は PAH の大気圈, '水圈, 土壤圏, 生物圈なぞのコンパートメント間の濃 度分布(4) を考察する場合の重要な物性值である。 Mackay ら (4)5) は污染物 の各コンバートメント間の濃度分布についてフガシティーを用い て考察している。この中で，常温で固体で㐫る物質の各コンパー トメント間の濃度分布は, 固体の蒸気圧でなく過冷却状態の液体 の蒸気压を用いて考察する必要があると述べている。また，一般 に気体が固体表面に物理吸着する過程は液化似似ていると考兄ら れている8。ししたがって，環境大気中に拈りる PAH の粉じんへ

大阪府公害監視センタ一, 537 大阪市東成区中道

1) R. E. Waller, Brit. J. Cancer, 6, 8(1952).

2) 松下秀鶴, 江角凱夫, 山田都夫, 分析化学, 19, 951(1970).

3) M. Katz, T. Sakuma, A.Ho, Environ. Sci. Technol., 12, 909(1978).

4) D. Mackay, S. Paterson, Environ. Sci. Technol., 15, 1006(1981).

5) D. Mackay, S. Paterson, ibid., 16, $654 \mathrm{~A}(1982)$.

6) D. Mackay, W. Y. Shiu, R. P. Sutherland, ibid., 13, 333(1979).

7) H. Yamasaki, K. Kuwata, H. Miyamoto, ibid., 16, 189(1982).

8) S. Brunauer, "The adsorption of Gases and Vapors, Physical Adsorption", Vol.1, Princeton University Press, N. J. (1945) p. 231.
の吸着現象》を考察する場合には，PAH，は常温では固体である が，仮想的に液体として取り扱い，過冷却状態に猢りるそれらの 液体の蒸気圧拉よび蒸発熱を用いることが有力ではないかと考兄 た。

PAH の過冷却状態における液体の蒸気圧および蒸発熱は，そ れらの固体の蒸気圧および蒸発熱から推定值としで求めることが できる(4)110)。PAH の固体の蒸気圧，蒸発熱の測定結果について はいくつかの報告11) 14)があるが，目的とする PAH の蒸気圧お よび蒸発熱がすべて測定されているわけではない。またこれま でに過冷却状態の液体の蒸気圧扣よび蒸発熱を直接測定した報告 はない。

本報では，過冷却状態の液体の PAH の蒸気圧および蒸発熱を ガスクロマトグラフ法で直接求める方法について検討した。ガス クロマトグラフ法で $25^{\circ} \mathrm{C}$ と打活る $\mathrm{PAH}$ の蒸気庄および蒸発熱 を求め, これらの結果を同温度に战ける固体の PAH の蒸気圧お よび蒸発熱から理論的に求めた過冷却状態の液体の蒸気圧拈よび 蒸発熱と比較した。また，PAH の蒸発熱を大気中に特ける $\mathrm{PAH}$ の粉じんへの吸着熱と対比し，熱力学的観点から環境大気中の PAH の粉じんへの吸着現象について考察した。

9) S. H. Yalkowsky, Ind. Eng. Chem. Fundam., 18, 108(1979).

10) C. T. Chiou, D. W. Schmedding, M. Manes, Environ. Sci. Technol., 16, 4(1982).

11) R. S. Bradley, T. G. Cleasby, J. Chem. Soc., 1953, 1690.

12) H. Hoyer, W. Peperle, Z. Elektorochem., 62, 61(1958).

13) N. Wakayama, H. Inokuchi, Bull. Chem. Soc. Jpn., 40, 2267(1967).

14) J. J. Murray, R.F. Pottie, C. Pupp, Can. J. Chem., 52, 557(1974). 


\section{2 理 論}

\subsection{PAH の過冷却状態における液体の蒸気圧および蒸発熱} の推定

温度 $T(\mathrm{~K})$ における $\mathrm{PAH}$ の過冷却状態の夜体の蒸気圧およ び蒸発熱は, 同温度における $\mathrm{PAH}$ の固体の蒸気圧および蒸発熱 から, 次式によって推定值として求めることができる。すなわち, PAH の過冷却状態における液体の蒸気圧および蒸発熱は, 融解 熱が求められている場合は (1)，(2) 式から，融解熱が求められ ていない場合は (3), (4) 式から求められる4)910)。

$$
\begin{aligned}
& \Delta H_{\mathrm{liq}}=\Delta H_{\mathrm{sol}}-\Delta H_{\mathrm{f}} \\
& \ln P_{\mathrm{liq}}=\ln P_{\mathrm{sol}}+\frac{\Delta H_{\mathrm{f}}}{R}\left(\frac{T_{\mathrm{m}}-T}{T T_{\mathrm{m}}}\right) \\
& \Delta H_{1 \mathrm{lq}} \approx \Delta H_{\mathrm{sol}}-0.0135 T_{\mathrm{m}} \\
& \ln P_{\mathrm{liq}} \approx \ln P_{\mathrm{sol}}+6.784\left(\frac{T_{\mathrm{m}}-T}{T}\right)
\end{aligned}
$$

ここで, $\Delta H_{\text {liq }}\left(\mathrm{kcal}^{15)} / \mathrm{mol}\right)$ は温度 $T$ における過冷却状態の液 体の蒸発熱, $\Delta H_{\text {sol }}(\mathrm{kcal} / \mathrm{mol})$ は温度 $T$ における固体の蒸発 熱, $\Delta H_{\mathrm{f}}(\mathrm{kcal} / \mathrm{mol})$ は融解熱, $P_{1 \mathrm{iq}}$ は温度 $T$ における過冷却状 態の夜体の蒸気圧, $P_{\mathrm{sol}}$ は温度 $T$ に扣ける固体の蒸気圧, $R$ は ガス定数, $T_{\mathrm{m}}$ は融点 $(\mathrm{K})$ である。

\section{2 ガスクロマトグラフ法による蒸気圧および蒸発熱の測定}

任意の温度に特ける試料物質の蒸気圧は（5）式で与えられ る $^{16)}$ 。

$$
\ln P_{1}=\frac{\Delta H_{1}}{\Delta H_{2}} \ln P_{2}+C
$$

ここで，1は試料，2 は基準物質であることを示して打り，Pは 蒸気圧, $\Delta H$ は蒸発熱，C は定数である。 $\Delta H_{1} / \Delta H_{2}$ は広い温度 範囲で一定である ${ }^{16) 17) の て ゙ ， ~} \Delta H_{1} / \Delta H_{2}$ と定数Cは（6）式を用 いて求めることがでさる ${ }^{16)}$

$$
\ln \left(\frac{R_{t 1}}{R_{t 2}}\right)=\left(1-\frac{\Delta H_{1}}{\Delta H_{2}}\right) \ln P_{2}-C
$$

ここで, $R_{t}$ はガスクロマトグラム上の保持時間である。 $\ln P_{2}$ に 対して $\ln \left(R_{t 1} / R_{t 2}\right)$ をプロットすると, 傾き $\left(1-\Delta H_{1} / \Delta H_{2}\right)$ および切片 $(-C)$ の直線が得られる ${ }^{16)}$ 。

\section{3 実 験}

\section{1 試 薬}

$\mathrm{PAH}$ および基準物質であるノナデカン（以下 $\mathrm{C}_{19}$ と略記する） は市販の試薬をそのまま用いた。

\section{2 ガスクロマトグラフィー}

ガスクロマトグラフは FID 付きヒューレットパッカード 5880 A 型, カラムはュニポート HP (60〜80メッシュ) に Aporane $\mathrm{C}_{87}$ を $10 \%$ 塗付したものを充媜した内径 $2 \mathrm{~mm}$, 長さ $1 \mathrm{~m}$ のス テンレススチール製カラムを用いた。カラム温度 $110 \sim 270^{\circ} \mathrm{C}$ の 間で, $10^{\circ} \mathrm{C}$ ごとに等温分析を行なった。各成分 $1 \mathrm{mg} / \mathrm{ml}$ のベン

15) $1 \mathrm{kcal}=4184 \mathrm{~J}$.

16) D. J. Hamilton, J. Chromatogr., 195, 75(1980).

17) D. F. Othmer, Ind. Eng. Chem., 32, 841(1940).
ゼン溶液 1〜10 $\mu l$ をガスクロマトグラフに注入した。各成分の 保持時間は見かけの保持時間からメタンの保持時間を差し引いた ものとした。試料注入後約 300 分まで測定し, 保持時間 0.2 分 以上の値を用いた。

\section{$3.3 \mathbf{C}_{19}$ の蒸気圧および蒸発熱の求め方}

$\mathrm{PAH}$ の蒸気圧を測定するための基準物質には $\mathrm{C}_{19}$ を用いた。 $\mathrm{C}_{19}$ の $110 \sim 270^{\circ} \mathrm{C}$ 間の蒸気圧は Antoine 定数 ${ }^{18)}$ を用いて計算 した。 $25^{\circ} \mathrm{C} に お け る ~ C_{19}$ (液体) の蒸気圧および蒸発熱は, Morecroft ${ }^{19}$ ) の測定結果（測定温度 $33 \sim 55^{\circ} \mathrm{C}$ ) から計算した。

\section{$3.425^{\circ} \mathrm{C}$ における $\mathrm{PAH}$ の蒸気圧および蒸発熱の求め方}

$110 \sim 270^{\circ} \mathrm{C}$ の間で, $\mathrm{C}_{10}$ の蒸気圧の対数に対して，同温度にお ける $\mathrm{C}_{19}$ に対する $\mathrm{PAH}$ の保持時間の比の対数をプロットし, (6)式の傾き $\left(1-\Delta H_{1} / \Delta H_{2}\right)$ と切片 $(-C)$ を求めた。 $25^{\circ} \mathrm{C} に$ 扣ける各 $\mathrm{PAH}$ の蒸発熱は, 傾き $\left(1-\Delta H_{1} / \Delta H_{2}\right)$ と $25^{\circ} \mathrm{C}$ に特 ける $\mathrm{C}_{19}$ の蒸発熱 $(21.8 \mathrm{kcal} / \mathrm{mol})$ から求めた。ついで, $\Delta H_{1} /$ $\Delta H_{2}, \mathrm{C}$ および $25^{\circ} \mathrm{C}$ に打ける $\mathrm{C}_{19}$ の蒸気圧 $\left(5.32 \times 10^{-5}\right.$

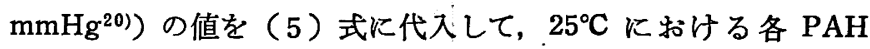
の蒸気圧を求めた。

\section{4 結 果}

表 1 に $110 \sim 270^{\circ} \mathrm{C}$ に拈ける $\mathrm{C}_{19}$ の保持時間および $\mathrm{C}_{19}$ に対 する各 $\mathrm{PAH}$ の保持時間の比を示す。表 1 の結果に基ついて, 3.4 の方法で求めた (6) 式の傾き $\left(1-\Delta H_{1} / \Delta H_{2}\right)$, 切片 $(-C)$ 拈よび $25^{\circ} \mathrm{C}$ に括ける各 $\mathrm{PAH}$ の蒸気圧, 蒸発熱の計算結果を表 2 に示す。

\section{5 考察}

\section{1 液相の選定}

ガスクロマトグラフに注入された試料成分の保持時間は，無極 性の夜相では試料成分の蒸気圧に反比例する。したがって, 蒸気 圧を測定するためには，できるだけ極性の小さい液相を選定する 必要がある。本実験では，ガスクロマトグラフのカラム充填剤と 乞て, 無極性の Aporane $\mathrm{C}_{87}$ を 60〜80 メッシュのユニポート HP に $10 \%$ 塗布したものを使用した。液相の極性を示す指標として McReynolds 定数が用いられ，この值が小さい液相の極性は小さ い。 Aporane $C_{87}$ は $250^{\circ} \mathrm{C}$ 以上で使用可能な液相の中では，最 小の McReynolds 定数を示し，炎の值は 71 である21。

\section{2 熱力学的考察}

(2)，(4) 式から求めた $25^{\circ} \mathrm{C}$ における PAH の過冷却状態に 打ける液体の蒸気圧 (以下 $\left(P_{1 \mathrm{iq}}\right)_{25}$ と略記する) の推定值を表 3 に示す。 $\left(P_{1}\right)_{25}$ は $25^{\circ} \mathrm{C}$ における $\mathrm{PAH}$ の固体の蒸気圧 (以下 $\left(P_{\mathrm{sol}}\right)_{25}$ と略記する)にくらべて大きい值を示し, アントラセン, クリセン, トリフェニレンなどの高融点の PAH では, $\left\{\left(P_{1}\right)_{25} \mid\right.$ $\left.\left(P_{\mathrm{sol}}\right)_{25}\right\}$ が 100 倍にも達する。一方, $\left(P_{1}\right)_{25}$ と $\left(P_{1 \mathrm{lQ}}\right)_{25}$ は近

18) F. D. Rossini, K. S. Pitzer, R. L. Arnett, R. M. Braun, G. C. Pimentel, "Selected Values of Physical and Thermodynamic Properties of Hydrocarbons and Related Compounds", Carnegie Press, Pittsburgh, Pennsylvania (1953) p. 373.

19) D. W. Morecroft, J. Chem. Eng. Data, 9, 488(1964).

20) $1 \mathrm{mmHg} \approx 133.3 \mathrm{~Pa}$.

21) J.W.Westcott, T. F. Bidleman, J. Chromatogr., 210 , 331(1981). 


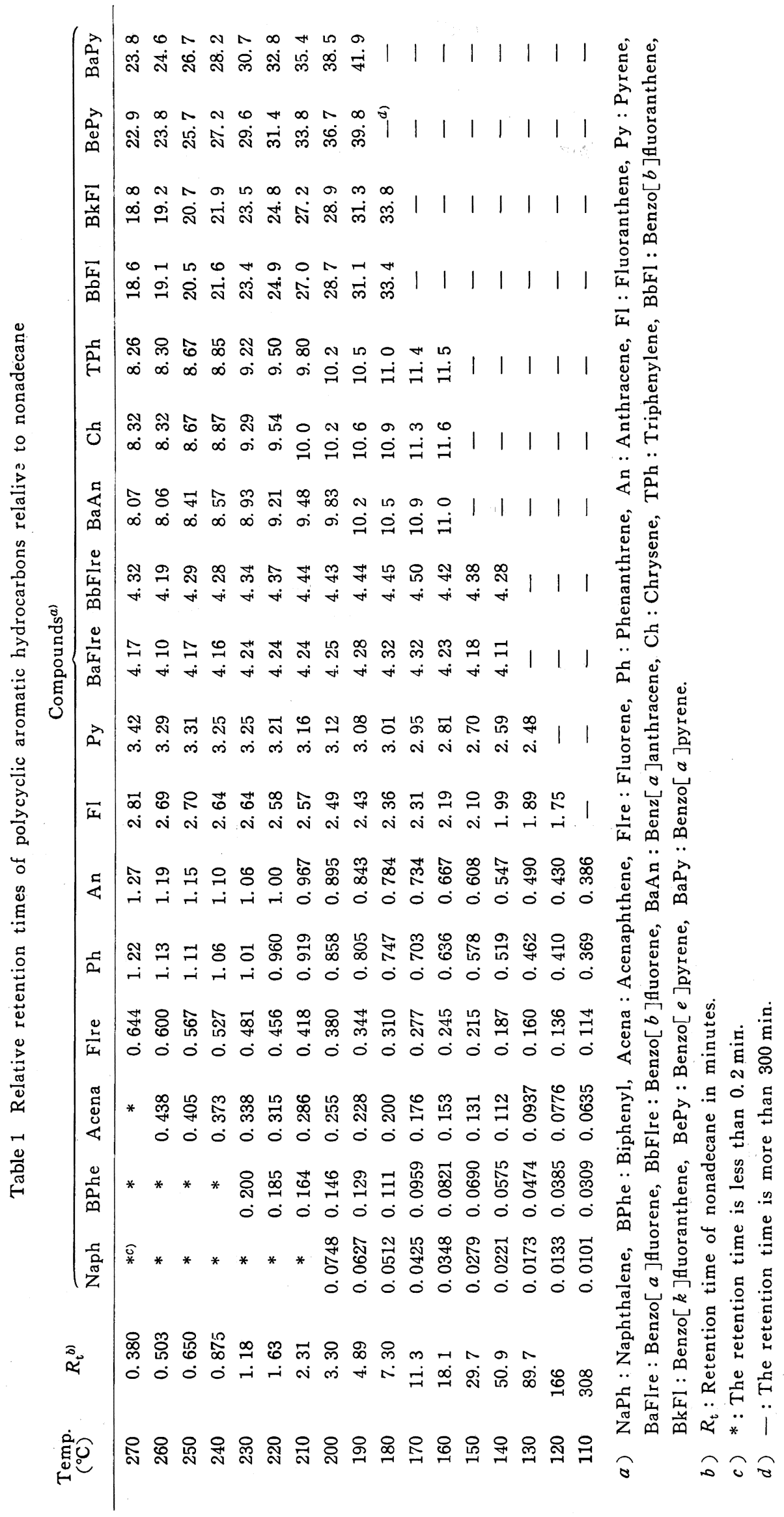


Table 2 Vapor pressure and heat of vaporization at $25^{\circ} \mathrm{C}$

\begin{tabular}{|c|c|c|c|c|}
\hline Compd. & $1-\Delta H_{1} / \Delta H_{2}{ }^{a)}$ & $-C^{a)}$ & $P_{1}(\mathrm{mmHg})$ & $\Delta H_{1}(\mathrm{kcal} / \mathrm{mol})$ \\
\hline Naphthalene & 0.409 & -3.810 & $1.34 \times 10^{-1}$ & 12.9 \\
\hline Biphenyl & 0.317 & -2.858 & $2.09 \times 10^{-2}$ & 14.9 \\
\hline Acenaphthene & 0.280 & -2.197 & $7.57 \times 10^{-3}$ & 15.7 \\
\hline Fluorene & 0.241 & -1.683 & 3. $06 \times 10^{-3}$ & 16.6 \\
\hline Phenanthrene & 0.166 & -0.656 & 5. $28 \times 10^{-4}$ & 18. 2 \\
\hline Anthracene & 0.165 & -0.607 & $4.95 \times 10^{-4}$ & 18. 3 \\
\hline Fluoranthene & 0.068 & 0.692 & $5.21 \times 10^{-5}$ & 20.4 \\
\hline Pyrene & 0.051 & 0.970 & 3. $34 \times 10^{-5}$ & 20.7 \\
\hline Benzo $[a]$ fluorene & -0.002 & 1.445 & 1. $23 \times 10^{-5}$ & 21.9 \\
\hline Benzo $[b]$ fluorene & -0.006 & 1. 490 & $1.14 \times 10^{-5}$ & 22.0 \\
\hline Benz $[a]$ anthracene & -0.084 & 2.521 & $1.88 \times 10^{-6}$ & 23.7 \\
\hline Chrysene & -0.087 & 2.570 & 1. $73 \times 10^{-6}$ & 23.8 \\
\hline Triphenylene & -0.088 & 2.570 & 1. $71 \times 10^{-6}$ & 23.8 \\
\hline Benzo[ $b]$ fluoranthene & -0.193 & 3.921 & 1. $58 \times 10^{-7}$ & 26.1 \\
\hline Benzo $[k]$ fluoranthene & -0.193 & 3. 929 & $1.56 \times 10^{-7}$ & 26.1 \\
\hline Benzo[e]pyrene & -0.209 & 4. 214 & $1.01 \times 10^{-7}$ & 26.4 \\
\hline Benzo $[a]$ pyrene & -0.214 & 4. 275 & $9.03 \times 10^{-8}$ & 26. 5 \\
\hline
\end{tabular}

Table 3 Vapor pressures at $25^{\circ} \mathrm{C}$ estimated from literatures

\begin{tabular}{|c|c|c|c|c|}
\hline Compd. & $\left(P_{11 q}\right)_{25}(\mathrm{mmHg})^{a)}$ & $\left(P_{\mathrm{sol}}\right)_{25}(\mathrm{mmHg})$ & $\underset{(\mathrm{kcal} / \mathrm{mol})}{\Delta H_{\mathrm{p}}}$ & $\mathrm{mp}(\mathrm{K})$ \\
\hline Naphthalene & $\begin{array}{l}\left.\left.2.72 \times 10^{-1} b\right), \quad 1.41 \times 10^{-1} c\right) \\
\left.2.62 \times 10^{-1} d\right)\end{array}$ & $\begin{array}{l}\left.\left.8.10 \times 10^{-2} b\right), \quad 4.19 \times 10^{-2} c\right) \\
\left.7.80 \times 10^{-2} d\right)\end{array}$ & $4.61^{f)}$ & 353.2 \\
\hline Biphenyl & 2. $\left.63 \times 10^{-2} b\right)$ & $\left.9.71 \times 10^{-3} b\right)$ & 4. $\left.43^{f}\right)$ & 344 \\
\hline Acenaphthene & $\left.7.67 \times 10^{-8}(c), \quad 1.04 \times 10^{-2} d\right)$ & 1. $\left.58 \times 10^{-3 c)}, 2.15 \times 10^{-8 d}\right)$ & $4.87^{g)}$ & 369.2 \\
\hline Fluorene & 4. $\left.\left.39 \times 10^{-8} b\right), 3.97 \times 10^{-8} d\right)$ & $\left.6.64 \times 10^{-4 b)}, 6.00 \times 10^{-4 d}\right)$ & $4.80^{h)}$ & 389 \\
\hline Phenanthrene & 7. $77 \times 10^{-4}$ b), $5.54 \times 10^{-4 d}$ & $1.70 \times 10^{-4 b)}, \quad 1.21 \times 10^{-4 d}$ & 4. $45^{f)}$ & 374 \\
\hline Anthracene & $5.81 \times 10^{-4}$ b),$\left.\quad 5.62 \times 10^{-4} d\right)$ & 6. $\left.\left.23 \times 10^{-6} b\right), \quad 6.03 \times 10^{-6} d\right)$ & 6. $89^{f)}$ & 489.2 \\
\hline Fluoranthene & 3. $\left.54 \times 10^{-5 c)}, \quad 6.51 \times 10^{-5} d\right)$ & 5. $\left.\left.04 \times 10^{-6} c\right), \quad 9.23 \times 10^{-6} d\right)$ & & 384 \\
\hline Pyrene & $\begin{array}{l}\left.\left.\text { 5. } 75 \times 10^{-5} b\right), 2.18 \times 10^{-5} c\right) \\
\left.\text { 3. } 90 \times 10^{-5} d\right)\end{array}$ & $\begin{array}{l}\left.\left.6.64 \times 10^{-6} b\right), 2.50 \times 10^{-6} c\right) \\
\left.4.50 \times 10^{-6} d\right)\end{array}$ & 4. $20^{f)}$ & 429 \\
\hline Benz $[a]$ anthracene & $\begin{array}{l}\left.\left.\text { 1. } 12 \times 10^{-6} c\right), 2.43 \times 10^{-6} e\right) \\
\left.\text { 4. } 52 \times 10^{-6} d\right)\end{array}$ & $\begin{array}{l}\left.\left.5.22 \times 10^{-8} c\right), 1.13 \times 10^{-7} e\right) \\
\left.2.10 \times 10^{-7} d\right)\end{array}$ & & 433 \\
\hline Chrysene & $\left.1.19 \times 10^{-6} c\right)$ & $\left.6.39 \times 10^{-9} c\right)$ & & 528 \\
\hline Triphenylene & 9. $\left.30 \times 10^{-7} c\right)$ & $\left.1.78 \times 10^{-8} c\right)$ & & 472 \\
\hline Benzo $[e]$ pyrene & $\left.1.83 \times 10^{-7} e\right)$ & 5. $68 \times 10^{-9 e)}$ & & 451 \\
\hline Benzo $[a]$ pyrene & 1. $\left.70 \times 10^{-7} e\right)$ & $5.63 \times 10^{-9 e)}$ & & 448 \\
\hline
\end{tabular}

$\left(P_{11 q}\right)_{25}$ : Vapor pressure at $25^{\circ} \mathrm{C}$ in supercooled liquid. $\left(P_{\text {sol }}\right)_{25}$ : Vapor pressure at $25^{\circ} \mathrm{C}$ in solid. $\Delta H_{\mathrm{f}}$ : Heat of fusion.

a) Calculated by equation (2) or (4). b) Reference 12). c) Reference 11). d) Reference 22).

e) Reference 14). f) Reference 10). g) Reference 23). h) Reference 24).

い值を示すものが多く，とくに縮合環数 4 以下の PAH では $\left(P_{1}\right)_{25}$

と $\left(P_{11 q}\right)_{25}$ がほとんど一致している。このことから, 本報で求 めた PAH の蒸気圧の值は過冷却状態の液体の蒸気圧であると考 えられる。また， $\left(P_{\mathrm{sol}}\right)_{25}$ はフェナントレン拉よびアントラセン， あるいはベンゾ $[a]$ あントラセン，クリセンおよびトリフェニレ ンなどの異性体間に执いて大きく異なるが， $\left(P_{1}\right)_{25}$ はほぼ同じ值 を示している。

22) W. J. Sonnefeld, W. H. Zoller, W. E. May, Anal. Chem., 55, 275(1983).

23) K. W. Sadowska, G. B. Stepnieska, W. M. Recko, Przem. Chem., 48, 282(1969).

24）化学大辞典編集委員会編, “化学大辞典”, Vol. 8 共立出版 (1963) p. 31.
（1），(3）式から求めた PAH の過冷却状態における洂体の 蒸発熱（以下 $\left(\Delta H_{1 i q}\right.$ ) と略記する) の推定值を表 4 亿示す。 $\left(\Delta H_{1}\right)_{25}$ と $\left(\Delta H_{1 \mathrm{lq}}\right)$ はベンゾ $[e]$ ピレンおよびベンゾ $[a]$ ピレ ン以外の PAH についてはほぼ一致した。

\section{3 大気中における PAH の粉じんへの吸着現象の考察}

環境大気中において，PAH は気相中および粉じん中に存在し

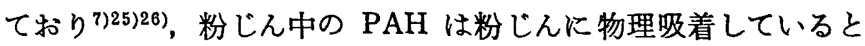

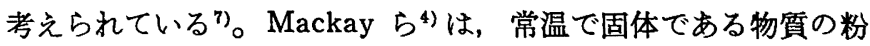
じん上に括ける吸着脱離現象は，固体の蒸気压ではなく過冷却状

25) W. Cautreel, K. V. Cauwenberghe, Atmos. Environ., 12, 1133(1978).

26）林 久緒, 島田ひろ子, 石田哲夫, 永田正信, 行方源六, 第 21 回大気污染学会講演要旨集, p. 355(1980), 
Table 4 Heats of vaporization estimated from literatures

\begin{tabular}{|c|c|c|}
\hline Compd. & $\left.\Delta H_{1 \mathrm{iq}}(\mathrm{kcal} / \mathrm{mol})^{a}\right) \cdots$ & $\Delta H_{\text {sol }}(\mathrm{kcal} / \mathrm{mol})$ \\
\hline Naphthalene & $\left.12.7^{b)}, 11.9^{c}, 13.5^{d}\right)$ & $17.3^{b)}, 16.5^{(c)}, 18.1^{d)}$ \\
\hline Biphenyl & $15.1^{b)}$ & $19.5^{b)}$ \\
\hline Acenaphthene & $14.6^{()}, 12.6^{()}$ & $19.5^{()}, 17.5^{d)}$ \\
\hline Fluorene & $15.0^{b)}, 16.4^{d)}$ & $19.8^{b)}, 21.2^{d)}$ \\
\hline Phenanthrene & 16. $2^{b)}, 18.3^{d)}$ & $\left.20.7^{b)}, 22.7^{d}\right)$ \\
\hline Anthracene & $17.5^{b)}, 15.0^{d)}$ & $24.3^{b)}, 21.9^{d)}$ \\
\hline Fluoranthene & $\left.19.3^{(c)}, 15.0^{d}\right)$ & $24.5^{c}, 20.2^{d)}$ \\
\hline Pyrene & $\left.\left.18.2^{b)}, 19.8^{c}\right), 17.6^{d}\right)$ & $22.4^{b)}, 24.0^{(c)}, 21.8^{d)}$ \\
\hline Benz $[a]$ anthracene & $22.8^{c)}, 21.3^{e)}$ & $28.6^{()}, 27.1^{e)}$ \\
\hline Chrysene & $21.9^{c)}$ & 29. $0^{c)}$ \\
\hline Triphenylene & $21.8^{(c)}$ & 28. $2^{(\text {) }}$ \\
\hline Benzo $[e]$ pyrene & $22.4^{e)}$ & $28.5^{e)}$ \\
\hline Benzo $[a]$ pyrene & $22.2^{e)}$ & 28. $3^{e)}$ \\
\hline
\end{tabular}

$\Delta H_{\text {liq }}$ : Heat of vaporization in supercooled liquid. $\Delta H_{\text {sol }}$ : Heat of vaporization in solid.

See Table 3 for the values of heat of fusion and melting point.

a) Calculated by equation ( 1 ) or ( 3 ). b) Reference 12). c) Reference 11). d) Reference 22). e) Reference 14).

態の夜体の蒸気圧を用いて考察する必要があると述べている。ま た，蒸気が固体表面に物理吸着する過程は液化の過程に似て括り， 一般に吸着熱は液化熱に近い値を示す。したがって，環境大気中 における $\mathrm{PAH}$ の粉じんへの吸着現象は, PAH の過冷却状態に おける夜体の蒸気圧および蒸発熱によって，うまく説明できるの ではないかと考えた。

表 5 に実際の大気で測定した気相中および粉じん中の $\mathrm{PAH}$ 量 から求めた $\mathrm{PAH}$ の粉じんへの吸着熱を示す7)。表 2,4 および 5 から明らかなように, PAH の粉じんへの吸着熱は $\left(\Delta H_{1}\right)_{25}$ に 近い值を示した。また林ら ${ }^{26)}$ は大気中におけるベンゾ $[a]$ なト ラセンとクリセンの気相中濃度に対する粉じん中濃度の比はほぼ

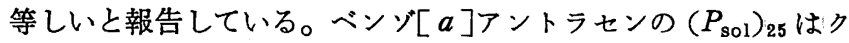
リセンの $\left(P_{\mathrm{sol}}\right)_{25}$ の約 10 倍であるが, 両者の $\left(P_{1}\right)_{25}$ はほぼ等


リセンの気相中濃度に対する粉じん中濃度の比がほぼ等しいこと は, $\left(P_{1}\right)_{25}$ を用いてうまく説明し得る。

以上のように, 大気中における $\mathrm{PAH}$ 蒸気の粉じんへの吸着現 象および気相中に存在する $\mathrm{PAH}$ と粉じん中に含まれている $\mathrm{PAH}$ の割合は，PAH の過冷却状態に和ける夜体の蒸気圧，蒸発熱を 用いてらまく説明することができると考えられる。

\section{6 結 語}

ガスクロマトグラフ法によって, 17 種類の $\mathrm{PAH}$ の $25^{\circ} \mathrm{C} に$ おける蒸気圧拈よび蒸発熱を求めた。これらの值は, 固体の蒸気 圧および蒸発熱から理論的に推定した $25^{\circ} \mathrm{C}$ における過冷却状態

Table 5 Heats of adsorption on the suspended particulate matter in the ambient air

Compd.

Phenantherene

Anthracene

Fluoranthene

Pyrene

Benzo $[\boldsymbol{a}]$ ]fluorene

Benzo[ $b]$ fluorene

Benz $[a]$ anthracene

Chrysene

Triphenylene

Benzo $[b]$ fluoranthene

Benzo $[k]$ fluoranthene

Benzo $[e]$ pyrene

Benzo $[a]$ pyrene

a) $\Delta H_{\mathrm{a}}$ : Heat of adsorption of PAHs on the suspended particulate matter: See reference 7 ).

の夜体の蒸気圧および蒸発熱とよく一致した。大気中における $\mathrm{PAH}$ 蒸気の粉じんへの吸着現象および気相中に存在する $\mathrm{PAH}$ と粉じん中に含まれている $\mathrm{PAH}$ の割合は, 本報で求めた $\mathrm{PAH}$ の蒸気圧，蒸発熱を用いてうまく説明することができた。

䅂りに，本研究に対して懇切な御指導をしていたたいた大阪府 立大学工学部乼川 裕教授, 貴重な御助言をいたたいた大阪府公 害監視センター杉前昭好博士，辻野喜夫氏に深く感謝いたします。 


\title{
Determination of Vapor Pressure of Polycyclic Aromatic Hydrocarbons in the Supercooled Liquid Phase and Their Adsorption on Airborne Particulate Matter
}

\author{
Hiroyasu Yamasaki*, Kazuhiro Kuwata and Yoshio Kuge \\ Environmental Pollution Control Center, Osaka Prefecture ; \\ Nakamichi, Higashinari-ku, Osaka-shi 537 Japan
}

Relative retentions of 17 polycyclic aromatic hydrocarbons (PAHs) to nonadecane $\left(R_{t 1} / R_{t 2}\right)$ were determined by isothermal gas chromatography on an Aporane $\mathrm{C}_{87}$ column at every $10^{\circ} \mathrm{C}$ from 110 to $270^{\circ} \mathrm{C}$. The relative heat of vaporization of PAHs $\left(\Delta H_{1} / \Delta H_{2}\right)$ was obtained by plotting $\ln \left(R_{t 1} / R_{t 2}\right)$ against logarithm of the vapor pressures of nonadecane $\left(\ln P_{2}\right)$. Then, the vapor pressure $\left\{\left(p_{1}\right)_{25}\right\}$ and the heat of vaporization $\left\{\left(\Delta H_{1}\right)_{25}\right\}$ of each PAH at $25^{\circ} \mathrm{C}$ in the supercooled liquid phase were calculated from these results using the absolule vapor pressure and the heat of vaporization of nonadecane $\left(\Delta H_{2}\right)$ at $25^{\circ} \mathrm{C}$ (equations 5,6$)$. The $\left(P_{1}\right)_{25}$ and $\left(\Delta H_{1}\right)_{25}$ values thus determined agreed with those calculated from the vapor pressure and the heat of vaporization at $25^{\circ} \mathrm{C}$ in the solid phase (Tables 3,4 ). The behavior of PAHs in the atmospheric environment such as adsorption of PAHs on particulates, and the ratios of PAHs in the vapor phase to those in the particulate phase, were well explained on the basis of $\left(P_{1}\right)_{25}$ and $\left(\Delta H_{1}\right)_{25}$ values in the supercooled liquid phase (Table 5). 